\section{Integralidad: tensiones y perspectivas}

Universidad de la República. Comisión Sectorial de Extensión y Actividades en el Medio. (2010). Cuadernos de Extensión.,(1). Montevideo: UdelaR. 108 páginas. Disponible en versión digital.

Reseñado por Agustín Cano Menoni

Universidad de la República, Uruguay. agustincanom@gmail.com
Integración de la docencia y la extensión / Reseña de libros

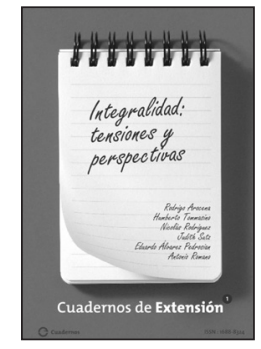

El libro que aquí se reseña reúne un conjunto de trabajos que dan cuenta de una coyuntura muy interesante de la historia extensionista de la Universidad de la República de Uruguay (UdelaR): el impulso de la política de la "integralidad" en el período 2006-2014. Dicha política, basada en algunos antecedentes históricos de la tradición extensionista de la universidad uruguaya, consistió en el desarrollo conceptual y el impulso programático de una concepción de la extensión integrada a la investigación y la enseñanza curricular, y preocupada por los aspectos éticometodológicos de un vínculo dialógico y transformador entre universidad y sociedad. Publicado en 2010, este libro condensa las discusiones teóricas y político-programáticas más relevantes y fecundas de dicha coyuntura de importantes transformaciones. Componen el libro cinco capítulos que analizan las "tensiones y perspectivas" de la integralidad desde una diversidad de enfoques, abordando el tema en sus dimensiones políticas, pedagógicas y epistemológicas. El entonces rector Rodrigo Arocena abre el libro con un prólogo donde se pregunta los "porqué, cuál y cómo" de la "curricularización de la extensión". El autor destaca la pertenencia de la extensión a la tradición reformista de la Universidad Latinoamericana, al tiempo que señala la necesidad, en la actualidad, de un segundo proceso reformista, que complete las tareas inacabadas por la reforma de Córdoba. En este proceso transformador, el autor asigna a la extensión, integrada a las demás funciones, un papel preponderante.

En sus "Tres tesis básicas sobre extensión y prácticas integrales", segundo capítulo del libro, Tommasino y Rodríguez plantean los aspectos conceptuales principales de la perspectiva de la integralidad vista desde el quehacer extensionista. Los autores sintetizan el proceso en curso en la UdelaR, las principales resoluciones universitarias que fueron pautando el desarrollo de esta política, así como información estadística sobre los primeros pasos de la implementación de la propuesta. Sobre esta base, proponen algunas referencias teóricas para fundamentar desde el punto de vista pedagógico y epistemológico el desarrollo de la integralidad de las funciones desde una concepción crítica de extensión, surgida de la tradición de la educación popular freireriana. En el tercer capítulo, Judith Sutz realiza un interesante planteo al formular a la integralidad "como espacio de preguntas recíprocas" entre diferentes tradiciones institucionales que conviven en la Universidad, evitando así el riesgo de una vana aspiración de borrar sus diferencias, y situando la potencia del diálogo a partir de ellas. La autora señala a su vez la importancia de este diálogo para revertir los aspectos más regresivos que el capitalismo académico ha operado sobre los modos de producción de conocimiento, valiéndose para ello de las ya clásicas nociones mertonianas en torno a los criterios normativos para el desarrollo de la investigación. Completan el libro un abordaje epistemológico y otro pedagógico.

El primero, a cargo de Álvarez Pedrosian, articula referentes teóricos de distintas corrientes filosóficas en una reflexión novedosa en torno a temas como el diálogo interdisciplinario, las relaciones sujetoobjeto de conocimiento y las lógicas diferenciales de los procesos de investigar, enseñar, aprender e intervenir. En el capítulo final del libro, Antonio Romano ensaya una mirada pedagógica e histórica sobre la integralidad, señalando algunas tensiones que ya es posible advertir en el proceso de su institucionalización, y recuperando referencias pedagógicas de la universidad medieval que ayudan a desnaturalizar nuestras ideas internalizadas en torno a los formatos de la enseñanza universitaria.

Aun cuando cambios institucionales regresivos puedan tornar adversos los contextos para el desarrollo de estas políticas, tanto en Uruguay como en la región resulta pertinente y necesario volver sobre este libro, revisitar sus planteamientos, retomar sus discusiones, reformular sus preguntas e intentar nuevas respuestas, para continuar avanzando en el camino de una formación universitaria integral comprometida socialmente. 